In the Special Issue on Multicultural Social Justice Leadership Development Guest Editor: Carlos P. Zalaquett, University of South Florida

\title{
Multicultural-Social Justice Leadership Strategies: Counseling and Advocacy with Immigrants
}

\author{
Rita Chi-Ying Chung and Fred Bemak \\ George Mason University \\ Tomoko Kudo Grabosky \\ Shippensburg University
}

\begin{abstract}
Immigration in the United States has been steadily increasing. Accompanying the largest influx of migrants into the U.S. during the past 20 years have been stereotypes and myths about immigrant populations. Growing concern about the shifting demographics has resulted in political debates on immigration, discrimination, hate crimes, and escalating controversy about undocumented people, all of which has caused strong proponents for and strong opponents against stringent migrant policies and legislation. Changing demographics, policies, and falsehoods about migrants have led to increased mental health concerns within the migrant groups that require counselors and psychologists to understand and effectively work with the unique needs of migrants in culturally responsive ways. This article dispels some of the myths about immigrants and provides examples of culturally responsive interventions specifically targeting the distinctive experiences of migrant populations. Recommendations on advocacy activities and strategies for this group are also provided.
\end{abstract}

Keywords: immigrants, refugees, forced migration, undocumented persons, multicultural, social justice, advocacy 
This article is based on the workshop on advocacy and social justice strategies for the rights of immigrants presented by the three authors. The U.S. began as a land of immigrants, and in recent times immigration has continued to increase every year. Since 2000, 10.3 million immigrants have arrived in the U.S., one of the highest seven-year periods of immigration in U.S. history (Camarota, 2007). Although migrants have historically moved to established ethnic communities in California, New York, Texas, Florida, New Jersey, and Illinois, in recent years there has been a substantial increase of immigrant groups who have migrated to the New England, Midwest, and Rocky Mountain regions (Chung, Bemak, Ortiz \& Sandoval-Perez, 2008). Given the rapidly growing immigrant population in the U.S.it is critical that counselors and psychologists attain and maintain current and culturally responsive strategies with this population.

This article is divided into six parts: 1) A brief overview of immigrants and their challenges, 2) a discussion on advocacy and social justice strategies in working with this group, 3) a description of the Multi-Level Model of Psychotherapy, Counseling and Social Justice (MLM) which is a culturally responsive model to assist immigrants and refugees in successful psychosocial adjustment and adaptation, 4) a presentation of a multicultural social justice career counseling approach for immigrants and refugees for finding gainful employment, 5) responses to the audiences' feedback of the workshop will be discussed, and 6) further actions and strategies and recommendations will be presented.

\section{Overview of Immigrants}

In 2007, the immigrant population (legal and illegal) in the U.S. is approximately 37.9 million or 1 in 8 persons in the U.S., which is the highest level in 80 years (Camarota, 2007). Comparatively in 19701 in 21 people in the U.S. was an immigrant, in 1980 it was 1 in 16, and in 1990 it was 1 in 13 (Camarota). Before we discuss the challenges of this population, it is important to note that the immigrant category consists of multiple groups. This includes: a) voluntary migrants (those who voluntarily migrant to the U.S. for more opportunities and a better life), b) undocumented people who entered the U.S. without legal papers, and c) those who are forced to migrate. The forced migration category is also comprised of a diverse group that includes survivors of human trafficking (Chung et al., 2008), refugees due to war or natural disasters, and also an increasing number of environmental refugees due to global warming and environmental racism.

It is estimated that more than 1 million people migrate legally to the U.S. each year and approximately one-half million enter illegally (Migration Information Resource, 2010). Given the dramatically growing immigrant population in the U.S., multicultural social justice counselors and psychologists are confronted with a challenge to provide culturally responsive services for this population that includes individual and community advocacy that leads towards harmonious race relations and the building of peaceful communities. To be effective with this population it is important to understand the challenges facing immigrants such as intolerance and xenophobia, which create barriers to forming peaceful and harmonious communities. Therefore, rather than a review of the psychosocial challenges in adjustment and adaptation for immigrant 
populations, this article focuses on stereotypes and myths of immigrant populations held by the host society, which are perpetuated through current political debates on immigration. A detailed discussion on the psychosocial challenges can be found in the counseling and psychology literature (e.g., Bemak \& Chung, 2008; Chung, et al., 2008; Prendes-Lintel \& Peterson, 2008, Short, Suzuki, Prendes-Lintel, Prendes-Lintel Furr, Madahushi \& Mapel, 2010; Marsella \& Ring, 2003; Mollica, 2006; Yakushko, 2009).

\section{Racism, Intolerance, and Xenophobia}

One major challenge that interferes with building peaceful interethnic interracial communities is the stereotypes and myths about immigrant groups held by the host society. Successful adjustment and adaptation of migrants and the development of harmonious communities are influenced by public reaction. Corporate media is a major source of information that substantially impacts the way the public views migrant populations. When immigrants or immigration is discussed in the U.S. there is oftentimes a focus on undocumented groups. Frequently, discussions about undocumented groups include myths and stereotypes of immigrants that consist of the wide-sweeping misperceptions that most immigrants have: entered the U.S. illegally; are taking non-immigrants' jobs; misusing resources and services; hurting the economy; and ultimately making life more difficult for U.S. citizens. These stereotypes are reinforced and perpetuated by the media coverage of undocumented people (Chung et al, 2008), and therefore promotes concerns about job security, economic sustainability, and the improper use of public resources and services(Chung et al.; Short et al, 2010; Yakushko, 2009).

Without a balanced perspective, these stereotypes and myths about immigrants breed fear, intolerance, and xenophobia. Mainstream media coverage in the U.S. is from Western Eurocentric and ethnocentric perspectives which emphasize and draw attention to immigrants as foreigners, aliens, strangers, and outsiders with unethical and immoral values, behaviors, and cultural practices. This can be seen with Latina/o Americans who are frequently suspected of being "illegal"; Asians Americans whose families have lived in the U.S. for many generations and continue to be viewed as perpetual foreigners (Wu, 2002); or Arab Americans who are perceived as potential "terrorists." In a speech delivered by former House Speaker Newt Gingrich at the National Federation of Republican Women, he described bilingual education as the "language of living in a ghetto" (Hunt, 2007). Attitudes such as this promote increasing legislative support for "English only" and other anti-immigrant laws, and illuminate how forms of individual and institutional racism can work in tandem to undermine the rights and psychological well-being of migrant populations (Chung et al. 2008). Simultaneously, the interaction of economically difficult times and current politics and political debates on immigration exasperate and highlight the myths, stereotypes, and fear of immigrants and reinforces the promotion of racism, discrimination, xenophobia, and intolerance (Marsella \& Ring, 2003). This can be seen with the controversial debate about immigration laws currently going on in Arizona and other parts of the country.

Critics of the Arizona immigration law SB 1070 argue that it codifies racial profiling and legalizes the harassment of all Latinos regardless of their legal status (Kennedy, 2010). Similar to the Arizona SB 1070, Florida's draft immigration bill directs law enforcement to check immigration status of suspected illegal aliens while enforcing other laws (Whittenburg, 2010), and Wisconsin is expected to introduce an immigration bill similar to Arizona in the beginning of 2011 (Kulinski, 
2010). One bill under consideration by Congress at the time of writing this article and is a further example of racism, discrimination, and xenophobia against U.S. immigrants is the DREAM Act, also known as the Development, Relief, and Education for Alien Minor Act (S. 729). The Act was originally introduced in 2001, and reintroduced in 2009. It is still under review by Congress. If passed, the DREAM Act will be a vehicle to gain legal status for students who have grown up in the U.S. with parents who are undocumented and who have no mechanism to obtain legal residency, even if they have lived most of their lives in the U.S. (National Immigration Law Center, 2010). Under the DREAM Act, the students with good moral character who came to the U.S. at age 15 or younger at least five years before the date of the bill's enactment would qualify for conditional permanent resident status upon acceptance to college, graduation from a U.S. high school or being awarded a GED in the U.S. (National Immigration Law Center, 2010). The opponents of the DREAM Act argue that Latino students have the highest school dropout rates so that passing the bill would result in an increase of uneducated Latinos in the U.S. (Cubias, 2010). Supporters of the bill dispute this contention, arguing that blocking the bill is essentially withholding education from young Latinos who are innocent people caught in the circumstances of their birth (Smith, 2010). As the U.S. debates this issue, many young Latinos remain trapped in the system due to fear, intolerance, and xenophobia.

\section{Advocacy and Social Justice Strategies}

Multicultural social justice counselors and psychologists are challenged with not only providing culturally responsive services for immigrants, but also to advocate for the rights of this group which ultimately will lead to building peaceful intercultural communities. Given the challenges in working with immigrants, this section will present advocacy and social justice strategies for working with immigrant populations. To be effective, counselors and psychologists must gain a full knowledge and understanding of the issues facing the immigrant population. Before describing social justice strategies, we will begin with a discussion on dispelling the myths and stereotypes of immigrants, with particular attention to undocumented migrants given the recent negative media attention and influence on public perceptions.

The first step for us to be effective is to recognize, acknowledge, and understand our own political countertransference, which may influence our clinical work with immigrants (Chung et al. 2008). Political countertransference is reinforced through the public media and without critical analysis of facts, myths and stereotypes has the potential to become an impediment to objective multicultural social justice counseling. Counselors and psychologists must be aware of their own political countertransference that may influence their perceptions of migrant clients. Similar to others in the public domain counselors and psychologists may also unconsciously internalize negative messages and hence buy into xenophobia and intolerance.

\section{Dispelling the Myth of Undocumented Migrants}

The belief that undocumented migrants create a strain on the economy and deplete resources is a major myth that has been perpetuated publically (Marsella \& Ring, 2003; Short et al., 2010; Yakushko, 2009). This viewpoint is oftentimes presented as fact without discussing an alternative perspective, neglecting to discuss contributions that undocumented migrants make to the larger society (Chung et al., 2008). Mainstream media tends to emphasize issues such as public education where undocumented children in 1993 to 1994 cost approximately $\$ 3.1$ billion in seven states (Arizona, California, Florida, Illinois, New Jersey, New York, and Texas (Capps \& 
Fix, 2005) or the $\$ 450$ million that this group consumes in Medicaid funds, or the $\$ 471$ million annual cost in prison expenditures (Capps \& Fix). These statistics and facts only present one part of a much more complex picture, and create and reinforce fear, intolerance, and xenophobia. What is not widely known by the public is that undocumented people contribute $\$ 1.9$ billion in taxes and billions more in consumer spending (Capps \& Fix) which is put towards education, health, and other social services for all U.S. citizens. In addition, although undocumented people pay into the social security system they do not have future access to social security, since only U.S. citizens receive this benefit. It is estimated that three-quarters of undocumented immigrants pay payroll taxes that contribute $\$ 6-7$ billion in social security funds annually that they are unable to claim (Porter, 2005).

Similar to all citizens, legal and undocumented migrants pay federal, state, and local taxes for income, property, and goods with expenditures projected between $\$ 90$ to $\$ 140$ billion a year, not including social security and Medicare taxes (National Immigration Forum, 2003). It is estimated that migrants' earn $\$ 240$ billion a year while using only about $\$ 5$ billion in public benefits (Federation of American Scientists [FAS], 1996). The approximately 7 million undocumented workers in the U.S. who are not entitled to benefits provided annual subsidies of $\$ 7$ billion, generated $\$ 56$ billion dollars in earnings, and produced $\$ 6.4$ billion in social security taxes which will never be claimed in 2002 (Porter, 2005). Subsequently the ratio between migrant taxes and use of public benefits and the taxes paid results in huge financial gains for the U.S. economy.

\section{Restricting Undocumented Migrants Creates Problems Rather than Solutions}

A major part of the political debate on undocumented migrants is on how to prevent undocumented people entering the U.S. One such proposal is to build a 2,000-mile wall along the U.S. border that may reduce the numbers of undocumented people crossing the border. Restricting undocumented migrants from coming to the U.S. has the potential to create problems rather than solutions. It raises questions such as whether an older more educated U.S. workforce is willing and able to work at low-paying jobs with poor working conditions, jobs that are currently held by migrants (National Council for La Raza, 2006). Presently there are approximately 9 million undocumented workers in the U.S. filling important gaps in the U.S. labor market (National Council for La Raza). Given these circumstances, it is critical that counselors and psychologists assume a social justice advocacy role when working with immigrants.

\section{Social Justice Advocacy Strategies}

As stated previously, one of the factors that promote intolerance and xenophobia towards immigrants is the fear that is generated from the myths and stereotypes of immigrant populations especially as it relates to taking resources from U.S. citizens, and this fear is exasperated during the difficult economy times. It is therefore important that counselors and psychologists work with the immigrant population and host communities regarding immigrant adjustment and adaptation while providing culturally responsive services that incorporates social justice advocacy work as it relates to the immigrant rights. The focus too often has been on a one-way immigrant education about "our way of life." This narrow view of education must expand to become more inclusive, fostering two-way communication and interventions with the migrant population, as well as, the host society, in order to eliminate xenophobia and 
intolerance and create united, cohesive, and peaceful communities and society. Adjustment issues involve the entire community with host communities adjusting to the newcomers and migrants adjusting to the new community. Thus, rather than a limited ethnocentric reaction to migrant groups about their cultural practices and beliefs about healing, it is important to work with the surrounding larger community. For example, child rearing has caused controversy and cultural clashes given different beliefs about discipline practices and raising children. It is critical that counselors and psychologists provide education to the migrant community about the laws of the U.S. and how to alter, adapt, and modify their practices to keep within the legal parameters of U.S. laws, while simultaneously educating mainstream society that some of these practices are not abusive but rather historical cultural methods of rearing children. For example, coining is an Asian traditional healing technique where a coin is rubbed on the shoulder, back and chest leaving temporary bruises on the body. The bruises have been misinterpreted in Western countries as child and elderly abuse (Chung \& Bemak, 2006).

It is also important and effective to use the media as a tool in social justice advocacy to build peaceful intercultural communities by focusing on positive stories and contributions of immigrants to society. To successfully achieve, this counselors and psychologists need to work in collaboration and form equal partnerships with community and spiritual leaders. The helping professional also must advocate within their profession for the use of culturally responsive interventions such as the Multi-Level Model of Psychotherapy, Counseling, Social Justice, and Human Rights (MLM) and the career program (both of which will be discussed in the next section), as well as, educate colleagues about the lack of culturally sensitive assessment measures such as DSM (Chung \& Kagawa-Singer, 1995).

Although this article focuses on migrants in general, it is important to briefly mention environmental refugees and victims and survivors of human trafficking, two groups who are forced to migrate. The article does not allow for in-depth discussion on these two groups, but the authors feel that it is important for multicultural social justice counselors to be aware of these two increasingly prevalent immigrant groups.

Related to the first group, environmental refugees, it is essential that counselors and psychologists take a stand and advocate stopping the effects of global warming. Deforestation, desertification, coastal flooding, shoreline erosion and other environmental problems are forcing people from the Pacific Islands, Africa, and Asia to flee their villages, towns, and countries. The International Red Cross estimates that 25 million people have already been forced to leave their homes due to the effects of global warming (Rogers, 2009). In fact, given the increase of natural disasters and subsequent displacement of hundreds of thousands of people with no place to go the United Nations University's Institute for Environment and Human Security is concentrating on concerns regarding environmental refugees and evaluating how best to support them (Cascio, 2005). The movement of people impacts migration patterns to the U.S. and subsequently counselors and psychologists must become proactive advocates to reduce the negative impact of global warming.

Similarly, it is essential that counselors and psychologist educate others about human trafficking victims and survivors. Human trafficking is not necessarily happening in other countries, but also in the U.S. (U.S. Trafficking in Persons Report, 2010). To effectively prevent human trafficking, it is important to advocate for tougher penalties for human traffickers, establish international laws related to human trafficking, and provide effective mental health services for 
trafficking survivors (Chung, 2009). Paradoxically the U.S. places economic sanctions on originating countries of trafficking victims which increases the likelihood of more people being trafficked as a result of increased poverty (U.S. Trafficking in Persons Report). Thus, the focus of advocacy should be not only be on the supply country but also on the demand countries, e.g., U.S. the European countries, Australia, etc. (Chung), especially since trafficking is fundamentally the economics of supply and demand.

The next section will present an intervention model the Multi-level Model of Psychotherapy, Counseling, Social Justice and Human Rights. This Model is a culturally responsive model geared towards working with psychosocial adjustment for refugee and immigrant populations from a multicultural social justice perspective.

\section{Multi-Level Model of Psychotherapy, Counseling, Social Justice, and Human Rights for Immigrants (MLM)}

One of the challenges for migrants is the psychosocial adjustment and adaptation to a new culture and country. Some immigrants and refugees are confronted with multiple challenges that range from dealing with their premigration stressors (i.e., trauma, loss of family, etc.) and trying to cope with postmigration resettlement (i.e., culture shock, finding gainful employment, language, change in family dynamics, etc.). It is therefore critical that counselors and psychologists provide culturally responsive services for this population. The MLM model is a culturally sensitive model based on social justice theory and human rights principles developed by the first two authors to work with immigrants and refugees. The MLM will be briefly described below. For a more in-depth discussion of the MLM please see Bemak, Chung and Pedersen (2003) and Bemak and Chung (2008).

The MLM redefines the role of counselors and psychologists to incorporate advocacy, consultation, human rights, social justice, indigenous healing, social networking, and heightened cultural responsiveness into more traditional culturally competent counseling practices. Utilizing the MLM necessitates an understanding of cultural, sociopolitical, historical, and help seeking behaviors of immigrant clients as well as the impact of pre and post-migration experiences. Counselors and psychologists must have a deep rooted understanding of the racial and ethnic identity of the immigrant client and oneself, as well as, current knowledge about the contextual political and social response to immigrants that have an impact on their mental health.

Two key factors that must be kept in mind are political countertransference, which was mentioned previously, and the psychological recoil effect, which was found in a national study by Bemak and Chung (1998),to occur when immigrants have stronger traumatic reactions when witnessing others being harmed than when they personally experience the same harmful situations. The MLM (Bemak \& Chung, 2008; Bemak et al., 2003) consists of five intervention levels which are briefly described below:

Level 1: Mental Health Education. This involves using psychoeducational interventions to assist the client in understanding the counseling process. It provides clients with a clear understanding of what is expected of them and what to expect of the mental health professional in the therapeutic encounter. 
Level 2: Individual, Group, and Family Counseling Interventions. In this level, counselors and psychologists incorporate culturally responsive individual, group, and family interventions within a social justice and human rights framework.

Level 3: Cultural Empowerment. In the capacity of advocates and consultants, counselors and psychologists expand their traditional roles and assist immigrant clients and their families to master the new culture (Bemak, 1989).

Level 4: Integration of Traditional and Western Healing Practices.It is critical that counselors and psychologists have a clear understanding and acceptance of cultural help seeking behaviors and traditional healing practices when providing counseling to migrant populations. A key aspect to this is appreciating traditional healing practices from immigrants' culture of origin and being able to develop clear linkages and partnerships with traditional healers.

Level 5: Social Justice and Human Rights Issues. Immigrants face numerous political, social, and systematic obstacles as a result of migrating to a different country. It is essential that counselors and psychologists work with immigrant clients to promote fair and equal treatment and equivalent access to resources and opportunities.

The authors have found the MLM to be highly effective in working with immigrant populations by incorporating culturally responsive counseling, social justice, human rights, cultural empowerment, and traditional healing practices. An extension of the MLM is the critical need for immigrants to successfully find gainful employment, which will be discussed in the next section.

\section{Multicultural Social Justice Career Counseling}

Stereotypes and myths can contribute and interfere with the work life of immigrants. Securing gainful employment and career is one of the most significant successful transitions for immigrants to a new country. Employment can facilitate the process of psychosocial adjustment, assist immigrants to establish roots in the new country, foster the development of a social network, and provide an opportunity to learn the culture and the language (Yakushiko, Backhaus, Watson, Ngaruiya, \& Gonzalez, 2008). However, immigrants frequently encounter unemployment and underemployment (Chung et al., 2008). They may experience downward occupational mobility due to the challenges of finding employment equivalent to their educational level and credentials. This is especially painful for immigrants who have previously held a professional position in their country of origin (Bemak \& Chung, 2008). The Center for Workforce Success (2006) reported that immigrants are disproportionately employed in physically demanding jobs and in industries where there is significant potential for injury. In addition, immigrants' earnings are usually lower than the U.S. median income (Larsen, 2004). Therefore, it is not surprising to find employment challenges resulting in significant stressors that impact immigrants' mental health (Finch, Catalano, Novaco, \& Vega, 2003; Grzywacz, Quandt, Arcury, \& Marin, 2005).

\section{Barriers to Employment}

Pre and post migration experiences constitute a major difference in employment experiences between immigrants and U.S. born citizens (Yakushko, et. al., 2008). The interplay of pre and 
post migration variables creates a wide range of individual and contextual barriers to immigrants' employment. Eight individual barriers to employment which immigrants face consist of: limited language and communication proficiency (Knouse, Rosenfeld, \& Culbertson, 1992; Mermin, 2008; Yost \& Lucus, 2002); lower education attainment (Fouad, 1995; Mermin, 2008; Konouse, et. al. 1992; Kossoudji \& Cobb-Clark, 1996); the perception that a lack of U.S. education is a barrier to employment (Mermin, 2008); loss of occupational status (Yost \& Lucus, 2002); limited knowledge and access to U.S. employment resources, information, and networks (Hincapie, 2009; Mermin, 2008; Shinnar, 2007); acculturative stress (Yakushuko, et. al. 2008 ); lack of transportation (Mermin, 2008); and cultural values (Gomez, et. al. 2001; Shinnar, 2007). Three contextual barriers to employment experienced by immigrants include: labor market conditions (Shinnar, 2007; Yost \& Lucus, 2002); immigration trends (Shinnar, 2007); and xenophobia, racism, and sexism (Yakushko, 2006; Yakushko, et al. 2008). These factors contribute negatively to immigrants' employment conditions and affect self-confidence and career outlook among immigrants (Yakushko, et. al. 2008).

Furthermore, for refugees there is another added challenge. Most refugees tend to come from war-torn countries and therefore may struggle with psychological and physical symptoms related to premigration trauma (Bemak \& Chung, 2008; Yakushko, et. al. 2008). In addition, a unique challenge for undocumented immigrants is the lack of identification or a social security number (Mermin, 2008), which contributes to constant fear of deportation and harsh living conditions (Yakushko, et. al. 2008).

The reality surrounding immigrants' employment situations creates a need and opportunity for counselors and psychologists to advocate for this population. An example of advocacy work is a career development program that the third author developed for refugees in south-central Pennsylvania to help promote equal job access. This program is described below.

Development of the Program. The idea for the program was developed during the third author's volunteer career counseling sessions with a refugee client who was a leader in the Bhutanese refugee community. The client expressed the need for community members to secure better jobs that reflected their qualifications and intellectual abilities. In addition, the pessimism about career prospects that permeated the Bhutanese community was shared, explaining that many of the refugees had college/graduate degree or work experience but were underemployed. A discussion about the needs of the community and brainstorming ideas for community career development workshops took place between the third author and the client.

It was clear from the discussion that the Bhutanese community differentiated between the concepts of work and career. For the refugees work was viewed as a means to ensure survival which is consistent with the career literature that suggests that having a career involves individuals who are privileged enough to seek employment to satisfy their abilities and interests (Blustein, McWhirter, \& Perry, 2005). The Bhutanese community's goal was to move beyond survival and obtain satisfying occupations that were aligned with their abilities and interest. Thus, the program developed by the third author was named "Career Development in the U.S.".

The third author's advocacy work involved contacting the local refugee resettlement agencies and requesting support to promote career workshops. She also contacted a non-profit community agency who provided space for the workshop, as well as, audio-visual equipment and refreshments. To assist with the workshops a volunteer employment assistant coordinator 
was secured who was able to partner with refugee services to manage the logistics. The third author offered pro bono services to facilitate the workshops while the Bhutanese client advertised the workshops in his community.

Social Justice Model Framework. Consistent with the social justice career counseling goals described by Toporek and Chope (2006), the three objectives of the career program were to: a) increase refugees' access to meaningful employment; b) eliminate refugees' barriers to career advancement; and c) to increase the opportunities for refugees' preparation for career development. Furthermore, the program also incorporated key elements of the Multi-level Model (MLM) of Psychotherapy, Counseling, Social Justice, and Human Rights (Bemak \& Chung, 2008) by including a group format to share common experiences, including psycho-education to facilitate an understanding of U.S. work culture and the employment system, aiming to promote their cultural empowerment and environmental mastery, and taking on a social justice advocacy role to address basic human rights and employment challenges among refugee clients.

The eight-week career development workshop was offered every other Saturday from 10 a.m. 12 p.m. The group consisted of 10 refugee clients. Nine were from Bhutan, and all had twoyear college degrees. One person was from Burkina Faso (West Africa) and had a master's degree. Their length of time in the U.S. ranged from two to three years. All of the Bhutanese participants worked at local warehouse distribution centers and some were taking courses at a local community college, while others had already completed a nurse's aid training course. Many of them hope to start their career in the human service field as teachers, nurses, or counselors. The workshops provided a variety of skill building opportunities, including resume and letter writing, as well as, effective communication through homework assignments, role playing, feedback, and video-taped mock interviews. The workshop topics included discussions about cultural differences and work norms, the job search process and resources, networking, how to "market" yourself, resume and letter writing, interview skills development, communication challenges, educational and training opportunities, and dealing with discrimination.

Multicultural Social Justice Requirements. In addition to the multicultural competencies counselors and psychologists must also be knowledgeable about pre-migration and postmigration challenges that impact immigrants' psychosocial adjustment to a new culture. It is critical for counselors and psychologists to understand issues, such as, reasons for migration, political and economic context of the home country, language barriers, loss and grief, changes in identity, dealing with xenophobia, discrimination, stereotypes, family relations and intergenerational conflicts, acculturation, cultural shock, survivor's guilt, mental and physical health problems, etc. (Bemak \& Chung, 2008). Simultaneously counselors and psychologists must have the skills and the ability to collaborate and work in interdisciplinary teams to assist with the complex pre and post-migration issues that impact immigrant's psychosocial adjustment and adaptation.

In addition, counselors and psychologists must be prepared to take on multiple roles depending on immigrant clients' needs, acculturation level, presenting problems, and goals.

Expanded roles may consist of consultant, advisor, teacher, therapist, facilitator, advocate, change agent, and case manager, as well as assuming the role as student/learner who needs to sometimes work in partnership with clients and their communities to "find out" rather than be 
the "expert" about culture and practices (Bemak \& Chung, 2008). Specific to career counseling is the knowledge and understanding of employment and immigration laws and policies, as well as, resources for translation services, international credential evaluation services, and English as a Second Language classes become critical for counselors when working with immigrant clients.

It is also important that counselors and psychologists are careful not only to educate immigrants about U.S. norms and customs, but to also focus on facilitating discussions about their own cultural norms with regards to the job search process, culture of work, communication, and interpersonal relationships. This discussion will aid counselors and psychologists in understanding immigrant clients' frame of reference, as well as validate their cultural values and practices. With this cultural information, counselors and psychologists can be culturally responsive in introducing U.S. employment information, norms and expectations of work, and how to access the employment system. Moreover, counselors and psychologists should emphasize that it is not necessary for immigrants to change who they are as they develop the knowledge and skills necessary for employment, but instead how to integrate the two different cultural norms and expectations of work. Immigrants need to have the opportunity and resources to be able to do this. By working out how they need to alter, adapt, change, and modify their cultural ways and to try out what works in the U.S. will help immigrants gain access to their desired employment. It is critical that counselors and psychologists respect immigrants' cultural identities while teaching them culturally-specific employment skills that work in the U.S. job market.

The next section will discuss the audiences' feedback and comments regarding the workshop.

\section{Reactions to the Comments and Feedback}

Overall, the participants stated that they learned counseling and social justice strategies to work with immigrant populations. Participants also clearly communicated their increased desire and enthusiasm to take personal and professional actions and become advocates for the rights of immigrants and refugees. For example, one participant expressed that they "learned strategies and models for working with immigrants". Another participant felt affirmed and stated: "How to work and address social justice with the immigrant community reaffirmed my position". Another participant stated: "Advocate...I would help to find more resources in my community and advocate for their rights".

In addition, there was strong support to participate in the "internationalization" of the counseling profession. For instance, the presenters recommended specific plans to modify pedagogy, such as including non-western theories of healing, incorporating case studies on immigrant populations, and organizing service learning activities to work with immigrants. Many participants declared their commitment to offer pro bono services to the immigrant and refugee populations. Examples of their comments include: "Identify community groups where I could work with the immigrant population"; "Sign up for a volunteer position at the counseling agency that focuses on diverse populations"; and "I would donate/volunteer my time to organizations that need culturally competent counselors with language skills." Some audience feedback depicted uncertainty about how to identify and develop concrete steps to become a change agent and how to become involved as advocates for immigrants and refugees. While the presenters intentionally avoided sharing too many personal experiences in this workshop, the participants' feedback requested that the presenters share more of their personal stories. 
Hence, our personal narratives would have been helpful for providing illustrations of what counselors and psychologists can do and to more clearly delineate challenges, effective strategies, and rewards for engaging in social justice in counseling.

\section{Future Actions and Strategies}

Future directions should be focused on providing resources and suggested action steps for those who want to engage in social justice actions. Supplying a list of immigrant and refugee service organizations that offer advocacy and counseling opportunities would be a good starting point. In addition, resources and ideas for incorporating social justice in counseling, supervision, and training can offer initial direction and support. To supplement these activities it is suggested that the development of an interest network and listserv on immigrant and international issues be developed for building a community of change agents dedicated to these issues. This group could meet at the ACA or APA annual convention for support, innovative ideas, and networking.

Many participants wished to hear more about examples of projects and activities as well as personal experiences of those who actively engage in social justice actions related to the immigrant and refugee population. To meet this need articles introducing teaching methodologies (i.e. service learning activities, case studies, projects, etc.), counseling approaches (collaborative projects, workshops, programs, etc.), and personal narratives of social justice leaders could be expanded in this journal, such as the 2009 Journal of Social Action in Counseling and Psychology, Invited Special Section on Personal Narratives on Activism for Social Justice and Systems Transformation, 2(1). These articles can offer an opportunity to explore innovative ideas as well as to inspire, affirm, and energize counselors and psychologists who are committed to multicultural social justice counseling.

Finally, it would be important to advocate training for linguistically competent counselors and psychologists to more effectively meet the needs of bilingual and multilingual immigrants. Monolingual counselors and psychologists must acquire the skills and understanding of how to effectively work with bilingual translators who assist in the counseling process. In turn, it is essential that counselors and psychologists understand the impact of immigrant clients who participate in counseling sessions using a language other than their native language, appreciating the effect on cognitive processing, emotional expression, comfort, selfpresentation, and self-identity. Monolingual counselors and psychologists must have the skills to incorporate this knowledge into their practice with bilingual immigrant clients, especially since the need for working with immigrants who have limited English proficiency or English as a second language is increasingly significant as U.S. immigration grows. Subsequently linguistically sensitive counseling is critical in working with immigrant populations.

In summary, given the large number of immigrants to the U.S. it is vital that counselors and psychologists not only provide culturally responsive services, such as utilizing the MLM model and the multicultural social justice career program, but also become advocates for this group, which requires having accurate information about the pre-immigration and post-immigration lives of their clients. Counselors and psychologists can use this information and effectively educate and dispel myths and stereotypes of immigrants and therefore prevent and intervene to challenge misconceptions that lead to xenophobia. Recommendations for working in migrant communities have been suggested so that counselors and psychologists go beyond just 
providing 50-minutetraditional counseling and psychotherapy sessions. To be effective with this population counselors and psychologists must provide a holistic approach to counseling and psychotherapy while using culturally responsive interventions that incorporate social justice and human rights within the migrant experience.

Contact information/Correspondence:

Rita Chi-Ying Chung, Ph.D.

George Mason University, Fairfax Campus

Robinson Hall A 335

4400 University Dr.MS 4B3

Fairfax, VA 22030

E-mail: rchung@gmu.edu

Rita Chi-Ying Chung, Ph.D. and Fred Bemak, Ed.D., are Professors in the Counseling and Development Program at George Mason University; Tomoko Kudo Grabosky, Ph.D. is at Shippensburg University.

\section{References}

Bemak, F. (1989). Cross-cultural family therapy with Southeast Asian refugees. Journal of Strategic and Systemic Therapies, 8, 22-27.

Bemak, F., \& Chung, R. C-Y. (1998). Vietnamese Amerasians: Predictors of distress and selfdestructive behavior. Journal of Counseling \& Development, 76, 452-458.

Bemak, F., \& Chung, R. C-Y. (2008). Counseling refuges and migrants. In P.B. Pedersen, J.G.Draguns, W.J. Lonner, \& J.E. Trimble (Eds.), Counseling across cultures $\left(6^{\text {th }}\right.$ ed., pp. 307-324). Thousand Oaks, CA: Sage.

Bemak, F., Chung, R. C.-Y., \& Pedersen, P. B. (2003). Counseling refugees: A psychosocial approach to innovative multicultural interventions. Westport, CT: Greenwood Press.

Blustein, D. L., McWhirter, E., \& Perry, J. C. (2005). An Emancipatory Communitarian Approach to Vocational Development Theory, Research, and Practice. The Counseling Psychologist, 33(2), 141-179. doi:10.1177/0011000004272268

Camarota, S. A. (2007). Immigrants in the United States, 2007: A profile of America's foreignborn population. Retrieved from http://www.cis.org/articles/2007/back1007.pdf.

Capps, R., \& Fix, M. E. (2005, November 1). Undocumented immigrants: Myths and reality. Retrieved from http://www.urban.org/url.cfm?ID=900898. 
Cascio, J. (October 12, 2005). Environmental refugees. Retrieved from http://www.worldchanging.com/archives/003618/hml.

Center for Workforce Success (2006). Improving workplace opportunities for limited Englishspeaking workers. National Association of Manufacturers. Retrieved from http://www.jff.org/publications/workforce/improving-workplace-opportunities-limite/255.

Chung, R. C-Y. (2009). Cultural perspectives on child trafficking, human rights and social justice: A model for psychologists. Counselling Psychology Quarterly, Special Issue: Models of Mental Health and Human Rights in Celebration of the $60^{\text {th }}$ Anniversary of The United Nations Declaration of Human Rights for All, 22(1), 85-96. doi:10.1080/09515070902761230

Chung, R. C-Y., \& Bemak, F. (2006). Counseling Americans of Southeast Asian Descent: The impact of the refugee experience. In C.C. Lee (Ed.).Multicultural issues in counseling: New approaches to diversity (p. 151-170), $3^{\text {rd }}$ edition. Alexandria, VA: American Counseling Association.

Chung, R.C-Y., Bemak, F., Ortiz, D.P., \& Sandova-Perez, P.A. (2008). Promoting the mental health of migrants: A multicultural-social justice perspective. Journal of Counseling and Development, Special Issue in Multicultural and Diversity Issues in Counseling, Special Issue, 38, 310-317.

Chung, R. C-Y., \& Kagawa-Singer, M. (1995). An interpretation of symptom presentation and distress: A Southeast Asian refugee example. Journal of Nervous and Mental Disease, 183(10), 639-648.

Cubias, D. (June 24, 2010). Why is anyone opposed to the Dream Act? Retrieved from http://humanrights.change.org/blog/view/why-is-anyone-oposed-to-the-dream-act.

Federation of American Scientists (1996). "Questioning Immigration Policy - Can We Afford to Open Our Arms?", Friends Committee on National Legislation Document \#G-606-DOM, January 25, 1996. Retrieved from http:www.fas.org/pub/gen/fcnl/immigra.html.

Finch, B.K., Catalano, R.C., Novaco, R.W., \& Vega, W.A. (2003). Employment frustration and alcohol abuse/dependence among labor migrants in California. Journal of Immigrant Health, 5, 181-186._doi:10.1023/A:1026119226083

Fouad, N.A. (1995). Career behavior of Hispanics: Assessment and career intervention. In F.T.L. Leong (Ed.), Career development and vocational behavior of racial and ethnic minorities(pp. 165-191). Mahwah, NJ: Lawrence Erlbaum.

Gomez, M. J., Fassinger, R. E., Prosser, J., Cooke, K., Mejia, B., \& Luna, J. (2001). Voces abriendo caminos (voices opening paths): A qualitative study of the career development of notable Latinas. Journal of Counseling Psychology, 48(3), 286-300. doi:10.1037/00220167.48.3.286 
Grzywacz, J. G., Quandt, S. A., Arcury, T. A., \& Marín, A. (2005). The work-family challenge and mental health: Experiences of Mexican immigrants. Community, Work \& Family, 8(3), 271-279. doi:10.1080/13668800500142236

Hincapie, M. (2009). Immigrants and employment. In F. Chuang-Muy, \& E.P. Congress (Eds.), Social work with immigrants and refugees: legal issues, clinical skills, and advocacy, (pp. 179-206). New York, NY: Springer Publishing Co.

Hunt, K. (April 1, 2007). Gingrich: Bilingual classes teach "Ghetto" language. The Washington, Post, p. A05.

Kennedy, H. (July 28, 2010). Arizona immigration law SB 1070 has most controversial parts blocked by federal judge. New York Daily News. Retrieved from http://www.nydailynews.com/fdcp?1290828013967.

Knouse, S.B., Rosenfeld, P., \& Culbertson, A.S. (Eds.). (1992). Hispanics in the workplace. Newbury Park, CA: Sage.

Kossoudji, A.S., \& Cob-Clark, D.A. (1996). Finding good opportunities within unauthorized markets: U.S. occupational mobility for male Latino workers. International Migration Review, 30 (4), 901-924.

Kulinski, C. (November 11, 2010). Rep. plans to introduce Arizona-like immigration legislation in Wisconsin. The Badger Herald. Retrieved from http://badgerherald.com/news/author/casey_kulinski/

Larsen, L.J. (2004). The foreign-born population in the United States: 2003. U.S. Census Bureau. Retrieved from http://www.census.gov/population/www/socdemo/foreign/cps2003.html.

Marsella, A. J., \& Ring, E. (2003). Human migration and immigration: An overview. In L.L. Adler \& U.P. Gielen (Eds.), Migration: Immigration and emigration in international perspectives (pp.3-22). Westport, CT: Preager.

Mermin, L.S.P. (2006). Living in America: Challenges facing new immigrants and refugees. In, K.E. Garrett (Ed.). Robert Wood Jonson Foundation. Retrieved fromhttp://www.policyarchive.org/handle/10207/bitstreams/21623.pdf.

Migration Information Resource (2010). Retrieved from http://www.migrationinformation.org/Usfocus/display.cfm?ID=723.

Mollica, R. F. (2006). Healing invisible wounds: Paths to hope and recovery in a violent world. Orlando, FL: Harcourt.

National Council of La Raza (2006). Fact sheet: Common myths about undocumented immigrants. Retrieved fromhttp://www.immigrantsolidarity.org/Documents/CommonMyths-ImmigrantsFINAL.pdf. 
National Immigration Law Center (September, 2010). Dream Act: Summary. Washington, DC: National Immigration Law Center.

Porter, E. (2005, April 5). Illegal immigrants are bolstering social security in billions. New York Times. Retrieved from http://www.nytimes.com/2005/04/05/business/05immigration.html?position=\&_r=1\&ad $\mathrm{xnnl}=1$ \&pagewanted=print\&adxnnlx=1277064125-0eyd6PZa1mqTKVyEhwQpKg.

Prendes-Lintel, M., \& Peterson, F. (2008). Delivering quality mental health services to immigrants and refugees through an interpreter. In L.A. Suzuki \& J.G. Ponterotto (Eds.), Handbook of multicultural assessment: Clinical, psychological, and educational applications ( $3^{\text {rd }}$ ed., pp. 220-244). Thousand Oaks, CA: Sage.

Rogers, S. (2009, February 15). Environment refugees. Retrieved from http://www.mnn.com/earth-matters/climiate-change/stories/environmentalrefugees.

Toporek, R.L., \& Chope, R.C. (2006). Individual, programmatic, and entrepreneurial approaches to social justice: counseling psychologist in vocational and career counseling, In R. L. Toporek, L.H. Gerstein, N.A. Fouad, G. Roysicar, and T. Israel, Handbook for Social Justice in Counseling Psychology (pp. 276-293). Thousand Oaks, CA: Sage Publications, Inc.

Shinnar, R. (2007). A Qualitative Examination of Mexican Immigrants' Career Development: Perceived Barriers and Motivators. Journal of Career Development, 33(4), 338-375. doi:10.1177/0894845307300413

Short, E.L., Suzuki, L., Prendes-Lintel, M., Prendes-Lintel Furr, G., Madabhushi, S., \&Mapel, G. (2010). Counseling immigrants and refugees. In J.G. Ponterotto, J.M. Casas, L.A. Suzuki, \& C.M. Alexander (Eds.), Handbook of multicultural counseling, (pp. 201-212). Thousand Oaks, CA: SAGE Publications.

Smith, J. (September 21, 2010). DREAM Act 2010 another controversy about immigration. Retrieved from http://cnmnewsnetwork.com/126638/dream-act-2010-anothercontroversy-about-immigration/

U.S. Trafficking in Persons Report (2010). Retrieved from http://geneva.usmission.gov/2010/06/14/trafficking-in-persons-report-2010/

Whittenburg, C. (November 26, 2010). Scott quiet on future of an immigration bill in Florida. The Tampa Tribune. Retrieved from http://www2.tbo.com/content/2010/nov/26/scottquiet-on-future-of-an-immigration-bill.

Wu, F. H. (2002). Yellow: Race in America beyond Black and White. New York, NY: Basic Books.

Yakushko, O. (2006). Career concerns of immigrant women: Issues and implications for career counseling. In W.B. Walsh, \& M.J. Heppner (Eds.), Handbook of Career Counseling for Women ( $2^{\text {nd }}$ ed., pp. 387-426). Mahwah, NJ: Lawrence Erlbaum Associate Publishers. 
Yakushko, O. (2009). Xenophobia: Understanding the roots and consequences of negative attitudes toward immigrants. The Counseling Psychologist, 37(1), 36-66. doi:10.1177/0011000008316034

Yakushko, O., Backhaus, A., Watson, M., Ngaruiya, K., \& Gonzalez, J. (2008). Career development concerns of recent immigrants and refugees. Journal of Career Development, 34(4), 362-396. doi:10.1177/0894845308316292

Yost, D., \& Lucas, M.S. (2002). Adjustment issues affecting employment for immigrants from the former Soviet Union. Journal of Employment Counseling, 39, 153-170. 